\title{
Brasil e Argentina: interação no meio virtual e formação (inicial e continuada) de professores de língua espanhola
}

\section{Brazil and Argentina: interaction in the virtual world and education (initial and continuing) of Spanish teachers}

Amábile Piacentine Drogui*

*Universidade Estadual do Paraná (Unespar), Apucarana, Paraná / Brasil amabile.piacentine@unespar.edu.br

https://orcid.org/0000-0002-2484-7850

RESUMO: Este artigo visa apresentar uma pesquisa que, articulando formação inicial e continuada, teve por objetivo avaliar se a interação, mediada por gêneros do meio virtual, em ambiente virtual de aprendizagem, pode resultar na mobilização de tipos discursivos que indiquem a aprendizagem de conteúdos propostos. Para geração dos dados, realizou-se uma intervenção de cunho formativo, que ocorreu por meio de um curso on-line - via plataforma Moodle - cujos participantes foram dezesseis brasileiros em formação continuada, que atuam como professores de língua espanhola em escolas públicas pertencentes ao NRE de Apucarana (PR), e dezesseis argentinos, em formação inicial, da Universidad Nacional de Córdoba (UNC). Os dados gerados são analisados levando em conta os gêneros como instrumentos psicológicos de mediação (SCHNEUWLY, 2010) e a interação como propiciadora de aprendizagem (VIGOTSKI, 1994, 2002). Os resultados apontam que a interação, entre tutora/ participantes e participante/participantes, mediada pelo fórum virtual, associado aos demais recursos disponibilizados no Moodle, propicia a aprendizagem de conteúdos propostos.

PALAVRAS-CHAVE: interação Brasil e Argentina; formação de professores de língua espanhola; plataforma Moodle; gênero fórum virtual educacional.

ABSTRACT: This article presents a research which, through the combination of initial and continuing education, aims at evaluating if the interaction, mediated by digital genres in a Virtual Learning Environment, can result in the mobilization of discursive types that indicate the learning of a proposed content. In order to generate data, there was an intervention of formative character, which happened by means of an online course - via Moodle Platform - whose participants were sixteen Brazilians in continuing education, who teach the Spanish Language in public schools belonging to the regional 
nucleus of the city of Apucarana, and sixteen Argentinians from Córdoba National University (UNC) in initial education. The data generated were analyzed taking into consideration the genres as psychological instruments of mediation (SCHNEUWLY, 2010) and the interaction responsible for fostering learning (VIGOTSKI, 1994; 2002). The results indicate that interaction, both among tutor/participants and participant/participants, mediated by the virtual forum, and associated to the other resources available at Moodle, can lead to the learning of the proposed content.

KEYWORDS: interaction Brazil and Argentina; education of teachers of Spanish; Moodle Platform; educational virtual forum genre.

\section{Introdução}

Para quem a língua e a linguagem são objetos de ensino, a exclusão dos gêneros do meio virtual em seus planejamentos pode resultar em uma aprendizagem claudicante. Schneuwly (2010, p. 21) afirma que o instrumento é o lugar privilegiado da transformação dos comportamentos, "explorar suas possibilidades, enriquecê-las, transformá-las são também maneiras de se transformar a atividade que está ligada à sua utilização”. Tanto para os que trabalham com língua materna quanto com línguas estrangeiras, se há mudanças nas formas de comunicação, há mudanças nas ferramentas de ensino e, consequentemente, nas atividades a elas relacionadas.

Araújo (2007, p. 15) argumenta que o interesse de diferentes pesquisadores pela internet "se justifica porque a internet gera novas formas de usar a linguagem, suscitando novos gêneros, inclusive inimagináveis até sua criação". Marcuschi (2010, p. 16) explica que o fato de a nova tecnologia reunir em um único espaço escrita, imagem e sonoridade interfere na natureza dos recursos linguísticos e justifica parte do seu sucesso.

As novas formas de linguagem do contexto virtual, no qual nos vemos inseridos, precisam fazer sentido pois, como afirma Coscarelli (2009, p. 13), já fazem parte de nós: "Vivemos o digital, somos o digital, fazemos o digital. Isso faz parte de nós, cidadãos inseridos no mundo contemporâneo, e se não faz, ainda, deveria fazer, ou vai fazer logo".

Levando em conta esses pressupostos, e elegendo a plataforma Moodle como ambiente virtual de aprendizagem (AVA), consideramos que a criação de um espaço, no qual a comunicação em língua espanhola fosse indispensável para haver interação, seria adequado para trazer respostas ao nosso questionamento: quais são as relações entre as interações, mediadas pelo gênero fórum virtual educacional e demais recursos disponibilizados no Moodle, e a aprendizagem de conteúdos propostos? 
Promovemos, então, por meio de um curso de extensão - vinculado ao projeto de pesquisa "(Educ)ação de professores de línguas: trabalho e desenvolvimento na práxis docente Linguagem e Educação" e à PróReitoria de Extensão da Universidade Estadual de Londrina (UEL) - um elo de comunicação entre professores brasileiros de Espanhol como Língua Estrangeira (ELE), em formação continuada, e alunos - futuros professores - dos cursos Profesorado de Español Lengua Materna y Lengua Extranjera e Licenciatura en Español, Lengua Materna y Lengua Extranjera da Facultad de Lenguas da Universidade Nacional de Córdoba (UNC), Argentina. A interação mediada é um dos fatores relevantes de nossa análise. A ontogênese, aspecto fundamental para compreensão dos estudos de Vigotski, reforça o caráter social da linguagem, que defendemos em nossa pesquisa.

A opinião dos participantes, sempre reveladora de suas formações axiológicas, é fundamental para identificar as características interacionais, geradoras de aprendizagem, que podem ser possibilitadas pelo AVA utilizado.

\section{Interação, mediação, aprendizagem e desenvolvimento}

Nessa seção, temos por objetivo refletir sobre a interação, mediada por instrumentos psicológicos, cuja finalidade é a aprendizagem e o desenvolvimento humano.

Valente (2013), fazendo um histórico sobre o papel da interação na aprendizagem, elenca três diferentes perspectivas científicas de tal conceito. A primeira diz respeito à proposta de interacionismo de Kant: o conhecimento como resultado da interação sujeito-objeto. A segunda, à construção do conhecimento a partir das relações do sujeito com o que o cerca: o conhecimento sendo construído na interação com o mundo em que se vive, com os objetos do cotidiano. Piaget identifica três tipos de conhecimento que o indivíduo constrói: físico (sujeito-objeto); lógicomatemático (reflexão sobre as informações coletadas, nível prático); e socialarbitrário (construído na interação com outras pessoas na sociedade). A

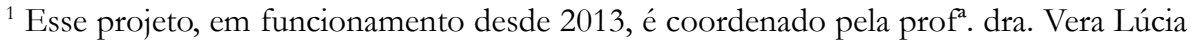
Lopes Cristovão. Abrange ações investigativas em diferentes polos do trabalho educacional: os alunos, os professores e as ferramentas de mediação. Também enfoca os tipos de interação e participação dos envolvidos nos processos investigados.
} 
terceira perspectiva é a preocupação de Vigotski em propiciar meios para a construção do conhecimento: o desenvolvimento humano está intimamente relacionado com o meio no qual se insere; a apropriação dos signos sociohistoricamente construídos e dos instrumentos psicológicos é determinante para a evolução humana.

Aderimos à perspectiva vigotskiana e defendemos que apenas as características biológicas ${ }^{2}$ dos seres humanos não lhes permitem compreender os elementos semióticos relativamente estabilizados na sociedade. É no contato com os pares mais desenvolvidos que ocorre a apropriação dos saberes já elaborados; o outro, com quem se interage, tem um papel fundamental na elevação do potencial de cada indivíduo. Se o processo de evolução é contínuo, a aprendizagem precisa ser permanente estamos em um espiral sem fim.

Criticando a obscuridade metodológica existente na relação entre aprendizagem e desenvolvimento, e admitindo sua complexidade, Vigotski (1994, p. 95) propõe uma nova abordagem na qual afirma que "aprendizado e desenvolvimento estão inter-relacionados desde o primeiro dia de vida da criança". O que difere o aprendizado pré-escolar do escolar é a sistematização deste segundo. Na proposta vigotskiana, a Zona de Desenvolvimento Proximal (ZDP) é o "conceito novo e de excepcional importância”, sem o qual ele acredita ser impossível resolver o problema.

Fazendo uma analogia com os gêneros textuais, podemos colocar que a criança, quando entra na escola, já domina uma série de gêneros e é capaz de selecioná-los adequadamente para se comunicar em seu cotidiano. Inicialmente, ela os internalizou imitando os adultos ou crianças maiores que a cercam. Para Vigotski (1994), a imitação não deve ser considerada uma simples reprodução mecânica das atividades dos adultos, mas sim como um momento no qual a criança, encontrando-se em uma ZDP, está exercitando suas capacidades.

\footnotetext{
${ }^{2}$ Não ignoramos que é o caráter biológico que possibilita ao ser humano evoluir, armazenando informações que lhe permitem um desenvolvimento diferente dos outros animais; entretanto, concordamos com Vigotski na defesa de que um ser humano isolado do convívio social, ou inserido em um meio que não lhe possibilite a aprendizagem dos construtos históricos, está fadado a muitas limitações que a história da humanidade já superou.
} 
O psicólogo explica que, para avaliar o desenvolvimento de uma criança, é preciso determinar pelo menos dois níveis: nível de desenvolvimento real e nível de desenvolvimento potencial.

O primeiro é o "nível de desenvolvimento das funções mentais da criança que se estabelecem como resultado de certos ciclos de desenvolvimento já completados" (VIGOTSKI, 1994, p. 111). Nesse caso, o indicativo de desenvolvimento é atribuído levando em conta somente o que a criança consegue fazer sem a ajuda dos outros, de acordo com sua idade. Vigotski (1994, p. 96) critica os pensadores que se restringiram a esse critério para avaliar o desenvolvimento infantil, ele observa que estes:

[...] nunca consideraram a noção de que aquilo que a criança consegue fazer com a ajuda dos outros poderia ser, de alguma maneira, muito mais indicativo de seu desenvolvimento mental do que aquilo que consegue fazer sozinha.

O segundo nível, de suma importância para os estudos do pesquisador, "é determinado através da solução de problemas sob a orientação de um adulto ou em colaboração com companheiros mais capazes" (VIGOTSKI, 1994, p. 97).

A ZDP é o espaço entre esses dois níveis, são as funções que estão em processo de maturação. Em síntese, a criança evolui com a ajuda de um "par" mais desenvolvido, sai de um ponto, chega a outro e reinicia seu percurso, conforme a Figura 1.

\section{FIGURA 1 - Zona de Desenvolvimento Proximal}
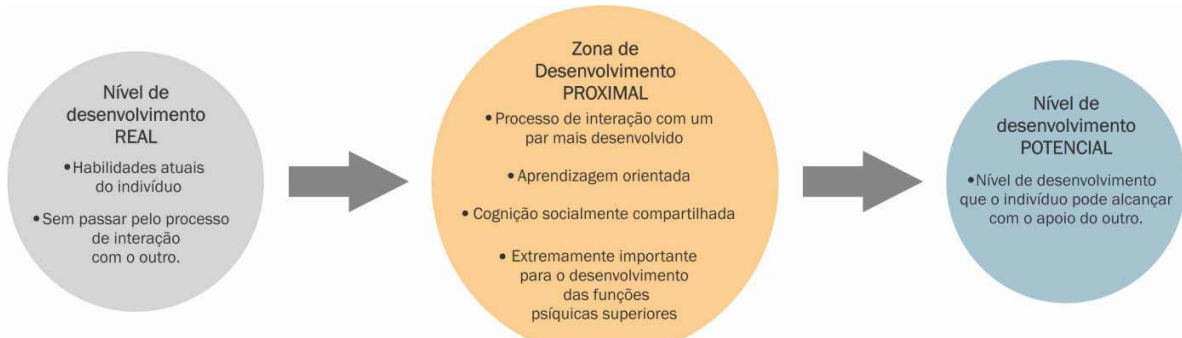

Fonte: elaborada pela autora, com base em Vigotski (1994)

Acreditamos que essa trajetória de aprendizado se estende à fase adulta, estamos em constante desenvolvimento, evoluindo por intermédio da interação direta ou indireta com "pares" mais desenvolvidos. Do mesmo 
modo, somos colaboradores na evolução de nossos "pares". Defendemos também que a imitação de modelos e modos de agir pré-existentes continuam por toda a vida, sempre que nos encontrarmos em uma ZDP.

O pesquisador russo faz também uma relevante distinção entre conceitos espontâneos ${ }^{3}$ (ou cotidianos) e conceitos científicos. Ao teorizar sobre os gêneros, Bakhtin (2003) também os classificou de forma parecida, denominando-os de gêneros primários e gêneros secundários, e Bronckart (2006) os apresenta como conhecimentos imediatos e mediatos.

Os conceitos espontâneos, gêneros primários ou conhecimentos imediatos são os que abrem caminhos para os científicos, secundários ou mediatos. O contrário também ocorre - os conceitos científicos fornecem estruturas para o desenvolvimento ascendente dos conceitos do cotidiano, rumo à consciência e à utilização deliberada. "Os novos e elevados conceitos transformam o significado dos conceitos inferiores." (VIGOTSKI, 2002. p. 80).

FIGURA 2 - Conceitos espontâneos/conceitos científicos

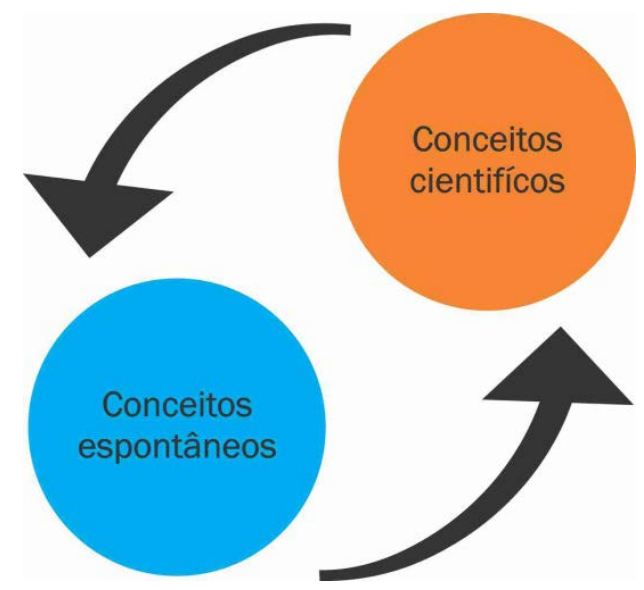

Fonte: elaborada pela autora, com base em Vigotski (2002)

O desenvolvimento dos conceitos científicos e das funções superiores da mente humana requer, além da interação com outros pares, a presença de

\footnotetext{
${ }^{3}$ Por não ser o foco de nossa pesquisa, não mencionamos os conceitos sincréticos, complexos, pseudoconceito e verdadeiro conceito. Explicações sobre esses termos podem ser encontradas em Vigotski (1994) e Friedrich (2011).
} 
elementos mediadores (instrumentos e/ou signos) que tornam as relações organismo/meio mais complexas. Oliveira (1993), em sua aprofundada leitura de Vigotski, afirma que este atribui elevada importância à interação social e à mediação simbólica no processo de construção das funções psicológicas superiores dos seres humanos.

Vigotski (2002) explica que os conceitos científicos são sistematizados (saber definir de maneira abstrata um objeto concreto do cotidiano é ser capaz de sistematizar), por isso só são interiorizados a partir do desenvolvimento das funções psicológicas superiores, este, por sua vez, só ocorre por meio de uma mediação que conduza à interiorização dos conceitos científicos. Nas palavras do autor: "Podemos agora afirmar, numa base sólida, que a ausência de um sistema é a diferença psicológica fulcral que distingue os conceitos espontâneos dos científicos (VIGOTSKI, 2002, p. 81).

Friedrich (2011, p. 49), também leitora e analista dos textos vigotskianos, afirma que, para o autor, o conceito científico tem relação tanto com o objeto quanto com outros conceitos; além de se apoiarem sempre nos conceitos cotidianos, "um conceito científico existe sempre no interior de um sistema de conceitos". A pesquisadora argumenta que, na visão de Vigotski, uma das tarefas principais da escola é o ensino dos conceitos científicos pois, por meio destes, ocorre o desenvolvimento das funções superiores da mente e vice-versa.

FIGURA 3 - Círculo constante do desenvolvimento

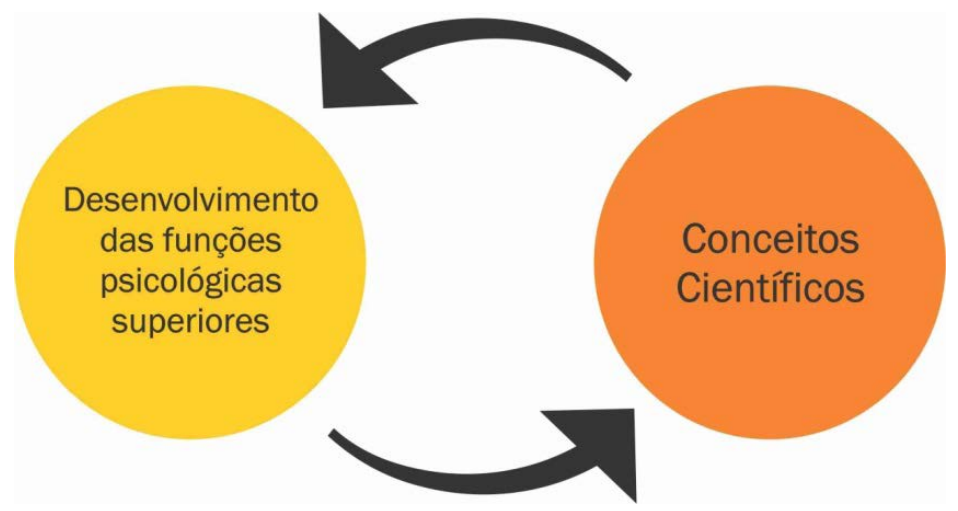

Fonte: elaborada pela autora, com base em Friedrich (2011) 
O processo de intervenção pedagógica deve ser construído tomando como ponto de partida o nível de desenvolvimento real do aprendiz. O professor, por sua vez, tem um papel explícito e relevante na ZDP, provocando avanços que não ocorreriam espontaneamente. A interação entre os alunos também influencia o desenvolvimento mútuo.

Tomando a linguagem como produto socio-historicamente construído, concentramos nossa pesquisa na interação, entre pessoas, mediada por instrumentos, sendo essas capazes de apropriarem-se destes a ponto de transformá-los, adequando-os ao seu espaço social de utilização (situação).

Oliveira (1993, p. 26-27) define mediação como "processo de um elemento intermediário numa relação; a relação deixa, então, de ser direta e passa a ser mediada por esse elemento". Numa crítica à perspectiva behaviorista, a pesquisadora afirma que o "processo simples estímuloresposta é substituído por um ato complexo, mediado" e define instrumento como o elemento interposto entre o trabalhador e o objeto de seu trabalho, entre o indivíduo e o mundo. O signo, por sua vez, "age como um instrumento da atividade psicológica de maneira análoga ao papel de instrumento no trabalho" (OLIVEIRA, 1993, p. 30).

Fundamentando-se em Bakhtin e também em Vigotski, Schneuwly (2010) defende que o gênero pode ser considerado um instrumento psicológico de mediação. Refutando a bipolaridade da psicologia geral, afirma que, para o interacionismo social, a atividade é necessariamente concebida como tripolar (Figura 4): "a ação é mediada por objetos específicos, socialmente elaborados, frutos das experiências possíveis" (SCHNEUWLY, 2010, p. 21). Além de ser elemento de mediação, o gênero pode ser fator de desenvolvimento das capacidades individuais. $\mathrm{O}$ autor argumenta que os instrumentos, por encontrarem-se entre o indivíduo que age e a situação (ou objeto) na qual ele age, determinam seu comportamento e influenciam sua percepção da situação na qual é guiado a agir. 
FIGURA 4 - Tripolaridade do instrumento

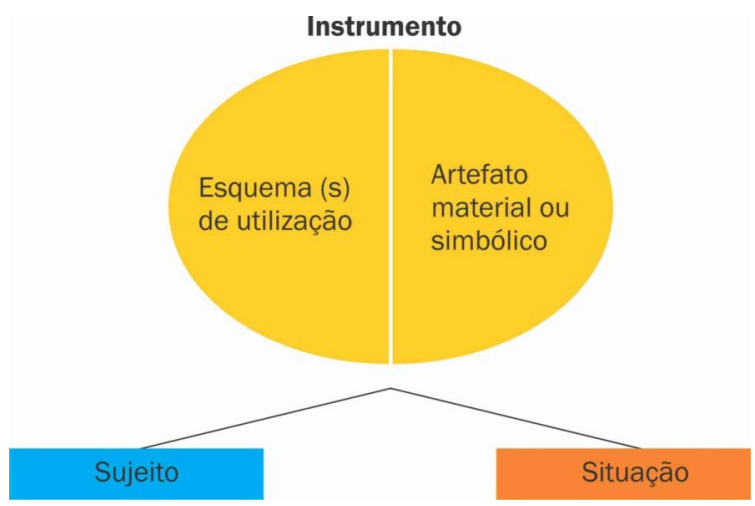

Fonte: Schneuwly (2010, p. 24)

O autor explica que, para que o instrumento se torne mediador da atividade, é preciso que o sujeito se aproprie dele, "ele não é eficaz senão à medida que se constroem, por parte do sujeito, os esquemas de sua utilização.” (SCHNEUWLY, 2010, p. 22). Enquanto essa esquematização não é internalizada, temos somente um artefato que ainda não foi instrumentalizado pelo sujeito.

No que se refere ao gênero, tratamo-lo como um elemento mediador que surge das interações sociais e, por meio delas, seguirá seu processo de evolução. Oliveira (1993) coloca que a mediação é essencial para tornar possíveis as atividades psicológicas voluntárias, intencionais, controladas pelo próprio indivíduo.

É o contato com o outro que desperta processos internos de desenvolvimento. "O ser humano cresce num ambiente social e a interação com outras pessoas é essencial ao seu desenvolvimento" (OLIVEIRA, 1993, p. 57).

Atualmente, com o advento da internet, existem novos caminhos para interagir socialmente e faz-se necessário refletir sobre essa nova maneira de interação e sua influência nos processos de aprendizagem e desenvolvimento.

\section{Gêneros do meio virtual}

Os gêneros do meio virtual, como enfatiza Marcuschi (2010, p. 15), não são totalmente novos, "a maioria deles tem similares em outros ambientes, tanto na oralidade como na escrita". No entanto, são suas 
peculiaridades que os transformam em outro gênero, com um novo nome para que seja identificado na esfera em que circula. $O$ bilhete deixado na mesa do gerente pode ser substituído por um e-mail enviado para seu endereço eletrônico. O primeiro é escrito com caneta em um pedaço de papel e espera-se que o destinatário o leia assim que o visualize em sua mesa; o segundo é digitado e segue virtualmente, pode ser lido em qualquer lugar em que o destinatário tenha acesso à internet e "abra seus e-mails".

Emprestando as palavras de Araújo e Costa (2007, p. 21), podemos afirmar que "tomamos a internet como um espaço sócio-discusivo que amplia as possibilidades de interação e incita o surgimento de vários gêneros discursivos".

No contexto de produção virtual, embora os enunciadores não se relacionem num mesmo ambiente físico (presencial), são indivíduos reais cujos objetivos comunicativos guiam a escolha do gênero. Para avisar um amigo de que está confirmada a partida de futebol, é comum o envio de um SMS pelo celular, sem preocupar-se com a formalidade; em contrapartida, para comunicar ao supervisor que a reunião com o cliente ficou agendada para a próxima semana, a praxe é o envio de um e-mail formal.

Entre as capacidades necessárias para o uso dos gêneros do meio virtual, está o conhecimento tecnológico, saber manusear as ferramentas que possibilitam a comunicação virtual. Por mais que, na esfera educacional, a maioria tenha contato frequente com a internet, faça parte de redes sociais e possua endereço eletrônico, não encontramos muitos profissionais que se considerem aptos para trabalhar utilizando AVA. Atualmente, muitas pesquisas reforçam a necessidade de letramento digital.

Ainda que o objetivo primordial de nosso trabalho não tenha sido o letramento digital, pudemos contribuir para que os participantes do curso, a partir da experiência de aprendizagem por meio de um ambiente virtual, desenvolvessem novos saberes nesse seguimento. E o ambiente virtual escolhido foi a plataforma Moodle.

\subsection{Plataforma Moodle}

O Moodle (Modular Object-Oriented Dynamic Learning Environment), ${ }^{4}$ é uma plataforma de aprendizagem a distância, baseada

\footnotetext{
${ }^{4}$ Ambiente modular de aprendizagem dinâmica orientada a objetos.
} 
em software livre. Foi criada em 1999 pelo australiano Martin Dougiamas, cientista da computação, como apoio a sua tese doutoral cuja ênfase está no uso de software livre como suporte para o ensino.

A primeira versão pública da plataforma Moodle apareceu em 2002, sendo rapidamente difundida e utilizada por milhares de instituições em todo o mundo. Atualmente, encontra-se presente em mais de 200 nações. Dados recentes da página moodle.org apontam o Brasil como o terceiro país com maior número de registros de uso da plataforma, com 5.293 sites registrados; em primeiro estão os EUA, com12.444e, em segundo, a Espanha, com 6.368. ${ }^{5}$ O Moodle está traduzido em mais de 75 idiomas, sendo o ambiente virtual líder no apoio ao ensino presencial, semipresencial e totalmente à distância.

A epistemologia sobre a qual se fundamenta o Moodle é a do construtivismo, paradigma que afirma que o conhecimento é construído gradativamente na mente do aluno, não transmitido como algo pronto. Por este motivo, o Moodle inclui ferramentas de apoio (chat, fórum, diário, wiki, oficinas) para que haja interação entre os tutores e os alunos de cada curso. López García e Lacleta (2006) argumentam que o fato de a plataforma estar baseada no mencionado paradigma de aprendizagem não limita outras possibilidades, "podem-se estabelecer cursos de acordo com diferentes abordagens, utilizando para isto os diferentes recursos e ferramentas que são oferecidos". ${ }^{6}$ Silva (2011, p. 125) complementa:

[...] este conjunto de ferramentas, além de conter recursos para a manipulação de textos e gráficos, contém dispositivos para organizar dados, gerenciar informações administrativas e conteúdos sobre acompanhamento da aprendizagem do aluno, considerando a participação dos educandos em testes, avaliações, processos de comunicação síncrona e assíncrona.

Desde sua criação, a plataforma passa por várias transformações. Sua natureza open source favorece sua rápida evolução, pois, com o crescente desenvolvimento tecnológico, usuários de todo o mundo contribuem para criação de novas ferramentas e atualização das já existentes. Atualmente, é possível inserir imagens, vídeos, vokis, slides e criar páginas coletivas, conhecidas por wikis.

\footnotetext{
${ }^{5}$ Informações disponíveis em: < https://moodle.org/stats> 16 jan. 2013.

${ }^{6}$ No original: "se pueden establecer cursos según diferentes enfoques utilizando para ello los diferentes recursos y herramientas que se ofrecen".
} 
Diferentes gêneros do meio virtual podem ser mobilizados nessa plataforma e, com a mediação adequada, podem promover interação que propicia aprendizagem e desenvolvimento.

Um dos gêneros do meio virtual mais utilizado no Moodle, e de extrema relevância para nossa pesquisa, é o fórum.

\subsection{Gênero fórum virtual educacional}

Uma das características de um gênero textual é a existência da interação. É preciso haver emissor/receptor, enunciador/destinatário (BRONCKART, 2006). Lima (2010, p. 9) argumenta que é evidente essa qualidade no gênero fórum virtual de discussão:

O e-gênero fórum de discussão possui esta característica de interação, considerando que é um gênero em que várias pessoas discutem um tema, geralmente determinado e conduzido por um organizador. Esse gênero permite que jogos de persuasão sejam desenvolvidos porque há sempre alguém tentando conseguir audiência para sua ideia defendida.

David et al. (2006), que também consideram o fórum virtual de discussão um gênero, incluem-no na categoria de gêneros assíncronos, que se destacam pelo fato de proporcionarem um tempo maior para a reflexão e elaboração das mensagens, aspecto de grande importância em atividades de caráter educacional. $\mathrm{O}$ usuário pode ter uma atitude responsiva ativa enunciada ou silenciosa, a partir do que lê, escolhe o que dizer ou não. Santos (2012) defende que:

O gênero textual fórum de discussão educacional propicia um saber-fazer relacionado à reflexão sobre práticas profissionais docentes e um saberdizer relacionado ao compartilhamento de experiências e à tomada de posição diante de determinada situação.

Consideramos que cada fórum virtual educacional se constitui um exemplar de texto empírico produzido por diferentes enunciadores e destinatários que alternam constantemente esses papéis. Optamos por utilizar post, postagem ou segmento de texto para nomear cada inserção feita pelos actantes.

Cristovão e Santos (2013), após selecionarem e analisarem dez sites com fóruns de discussão educacional, voltados para o ensino de inglês, descrevem as características gerais desse gênero, tendo como base os procedimentos de análise do interacionismo sociodiscursivo (ISD). 


\section{QUADRO 1 - Panorama do gênero fórum virtual educacional}

\begin{tabular}{|c|c|c|}
\hline Contexto de produção & Infraestrutura geral & $\begin{array}{l}\text { Mecanismos } \\
\text { enunciativos }\end{array}$ \\
\hline $\begin{array}{l}\text { - Lugar físico e momento de produção: } \\
\text { variam de acordo com os participantes. } \\
\text { - Espaço social: sites cujo objetivo } \\
\text { principal é a promoção de ensino/ } \\
\text { aprendizagem de língua inglesa e de } \\
\text { material de apoio. } \\
\text { - Enunciadores e destinatários: } \\
\text { professores, alunos-aprendizes de } \\
\text { inglês ou, ainda, alunos-professores } \\
\text { aprendizes de inglês. } \\
\text { - Quadro interacional da formação } \\
\text { social: marcado pelo hibridismo. No } \\
\text { papel social de professor de língua } \\
\text { inglesa, as discussões centram-se } \\
\text { na esfera profissional; no papel } \\
\text { social de pesquisador em estudos da } \\
\text { linguagem, as discussões centram-se } \\
\text { na esfera acadêmica; no papel social } \\
\text { de aluno-aprendiz de língua inglesa, as } \\
\text { discussões centram-se na esfera escolar; } \\
\text { no papel social de usuário da internet, } \\
\text { as discussões centram-se na esfera } \\
\text { digital. } \\
\text { - Objetivos: discutir aspecto teórico } \\
\text { prático do ensino de língua inglesa e/ } \\
\text { ou educação do professor de língua } \\
\text { inglesa (objetivo de cunho mais } \\
\text { acadêmico); sanar dúvidas relativas ao } \\
\text { uso da língua (objetivo de cunho mais } \\
\text { pragmático); compartilhar ideias e/ou } \\
\text { questionamentos acerca do ensino de } \\
\text { língua inglesa (objetivo de cunho tanto } \\
\text { acadêmico quanto pragmático). } \\
\text { - Temas mais recorrentes: ensino de } \\
\text { língua inglesa, gramática de língua } \\
\text { inglesa, compreensão e produção oral e } \\
\text { escrita e vocabulário em língua inglesa. } \\
\text { - Presença ou não de moderador, de } \\
\text { acordo com a política adotada pelo site. }\end{array}$ & $\begin{array}{l}\text { - Organização discursiva: identidade } \\
\text { da instituição ou pessoa responsável } \\
\text { pelo site } \rightarrow \text { Tópico gerador com } \\
\text { informações do proponente e data } \\
\rightarrow \text { Respostas e informações sobre o } \\
\text { autor de cada postagem, e a data. } \\
\text { - Organização da postagem: o título } \\
\text { é sempre o primeiro a aparecer, } \\
\text { sendo uma frase declarativa ou uma } \\
\text { pergunta; buscando sempre a adesão } \\
\text { do interlocutor. Nas postagens- } \\
\text { resposta, o título normalmente é } \\
\text { repetido, pode ocorrer a renomeação } \\
\text { por algum usuário. } \\
\text { - Elementos multimodais: imagens e } \\
\text { layout predeterminado. } \\
\text { - Ocupação das laterais por } \\
\text { propagandas direcionadas ao } \\
\text { público-alvo. } \\
\text { - A maior parte da interação se dá } \\
\text { por meio do uso do texto verbal. } \\
\text { A linguagem não verbal, apesar de } \\
\text { existente, não é preponderante. } \\
\text { - Tipo de discurso predominante: } \\
\text { discurso interativo (implicado e } \\
\text { conjunto). Encontrou-se em menor } \\
\text { escala o uso de discurso teórico, } \\
\text { encaixado para sustentar a opinião, } \\
\text { e alguns trechos de relato interativo } \\
\text { com a função de relatar a experiência } \\
\text { do agente produtor. } \\
\text { - Funções das sequências } \\
\text { encontradas: a explicativa, a dialogal } \\
\text { (conversa escrita) e a argumentativa. }\end{array}$ & $\begin{array}{l}\text { - As vozes do } \\
\text { autor empírico e as } \\
\text { vozes sociais são as } \\
\text { mais recorrentes. } \\
\text { - Vozes sociais } \\
\text { mais recorrentes: a } \\
\text { instituição escolar } \\
\text { na qual trabalha } \\
\text { ou estuda; pais de } \\
\text { alunos; colegas } \\
\text { de profissão, e de } \\
\text { esfera acadêmica. }\end{array}$ \\
\hline
\end{tabular}

Fonte: elaborado pela autora, com base nos estudos de Cristovão e Santos (2013) 
Substituindo o termo "língua inglesa" por línguas estrangeiras, temos um perfil dos modelos de fóruns educacionais abertos nessa área de ensino.

A situação de produção linguageira dos fóruns educacionais analisados por Cristovão e Santos (2013, p. 277-278), é resumido da seguinte maneira:

Um indivíduo, no papel de professor, aluno-aprendiz ou aluno-professor, inscreve-se numa comunidade virtual com o objetivo de compartilhar sua opinião, dúvida, ideia e/ou posição com interlocutores também interessados naquele tema. Os fóruns são organizados em forma de postagens, com thread principal e respostas subsequentes, e circulam na esfera virtual. A interação dos participantes é assíncrona, podendo ser moderada ou não.

De acordo com os pesquisadores, a análise dos textos os levou a concluir que o fórum, por propiciar uma situação real de comunicação, configura-se como um excelente espaço para o agir do professor, visto que nesse espaço ele atua como cidadão.

\section{$4 \mathrm{O}$ curso e suas relações teórico-metodológicas}

Tomamos como base os valores ontológicos defendidos pelo ISD, teoria que conceitua a língua como um sistema em constantes mudanças, viva, não estática, nem esperando pacientemente para ser analisada; somos influenciados por ela e a influenciamos. A linguagem, por sua vez, não é concebida como algo isolado do meio de produção, não é possível ditar significados extremamente fixos para uma palavra; o sujeito que dela se apropria, o contexto no qual ela se insere, para quem se dirige, em que forma (estrutura) é apresentada e em que momento da história se manifesta vão determinar sua significação (BAKHTIN, 2003). O realismo é histórico (BAKHTIN; VOLOCHINOV, 1986), influenciado por diversos valores. Para o ISD o significado se constrói nas interações, o indivíduo é um ser primeiramente social, é a consciência da existência do outro que faz com que o eu seja construído (BRONCKART, 2003, 2006).

Esses axiomas nos guiaram para uma pesquisa teórico-crítica, cuja epistemologia ancora-se na subjetividade, produzindo descobertas que não se pretendem imutáveis, mas buscam sua validade ao ressaltar os valores que 
as permeiam. De acordo com os estudos de Lincoln e Guba (2006, p. 180), o teórico crítico está entre os que têm:

[...] como primeiro campo de interesse exatamente o conhecimento social subjetivo e intersubjetivo e a construção ativa e a concriação desse conhecimento pelos agentes humanos, o qual é produzido pela consciência humana.

Como as demais investigações pertencentes a esse paradigma, este trabalho tem seu ponto de contraposição. Estamos na contramão dos estudos isolados do eu, da homogeneização dos seres, do individualismo e do cognitivismo esvaziado do social. Kincheloe e McLaren (2006, p. 286) afirmam que os pesquisadores críticos que compreendem a linguagem como "uma prática social instável, cujo significado altera-se dependendo do contexto no qual é empregada" são contrários à visão de neutralidade e descrição do mundo real; e que "A partir de uma perspectiva crítica, as descrições linguísticas não servem simplesmente par explicar o mundo, mas para construí-lo".

A teoria crítica não concebe a linguagem com objetivo de descrição do mundo real, pois, para este paradigma, tal apreensão não é possível; não existe nenhuma interpretação pura. Faz necessária a reconstrução da realidade, que tem sua validade quando considerados os valores envolvidos na pesquisa.

Tendo como fundamento esses princípios, construímos uma realidade de ensino para, posteriormente, analisá-la, organizamos o curso $^{7}$ on-line conforme o Quadro 2.

${ }^{7}$ O curso ocorreu de março a julho de 2013. 


\section{QUADRO 2 - Panorama geral do curso}

\begin{tabular}{|c|c|}
\hline $02 /$ & $\begin{array}{l}\text { - Início do curso com encontro presencial em Apucarana, com os professores } \\
\text { brasileiros. } \\
\text { - Participação em um fórum educacional aberto. } \\
\text { - Orientações para acesso à plataforma Moodle. } \\
\text { - Envio de tutoriais para acesso ao Moodle, para brasileiros e argentinos. }\end{array}$ \\
\hline $04 / 03$ a $14 / 03$ & - Apresentação na plataforma Moodle por meio do fórum "Presentación". \\
\hline $12 / 0$ & $\begin{array}{l}\text { - Leitura do texto "Repensando la Interacción”, da Charge "Educative } \\
\text { Innovéision" e participação no fórum: “¿Nuevos enfoques o nuevos medios?". }\end{array}$ \\
\hline $24 / 0$ & $\begin{array}{l}\text { - Com base em dois vídeos de anúncio publicitário comercial, reflexão inicial } \\
\text { sobre os conceitos de língua, linguagem, gêneros, contexto de produção e ensino } \\
\text { de línguas. } \\
\text { - Participação no fórum: “Conceptos". }\end{array}$ \\
\hline $26 / 0$ & $\begin{array}{l}\text { - Atividades em grupo temáticos: } \\
1 \text { - Géneros/textos } \\
\text { 2-Contexto de producción } \\
3 \text { - Enseñanza de lenguas } \\
4 \text { - Los impactos sociales de los textos } \\
\text { - Capacidades de lenguaje } \\
\text { - Cada grupo teve por atividades: a leitura de textos relacionados ao seu tema, } \\
\text { discussão no fórum do grupo, produção de um resumo e elaboração de uma } \\
\text { questão para propor a todos os participantes do curso. }\end{array}$ \\
\hline $15 /($ & $\begin{array}{l}\text { - Proposta de questões dos grupos para todos os participantes. Cinco fóruns } \\
\text { ocorrendo simultaneamente. } \\
\text { - Leitura dos resumos para facilitar a compreensão das questões. }\end{array}$ \\
\hline $15 / 05$ a $27 / 05$ & $\begin{array}{l}\text { - Reflexão sobre o trabalho realizado. Participação no fórum "El género fórum } \\
\text { virtual y sus imbricaciones". } \\
\text { - Participação em um fórum virtual educacional aberto para comparar as } \\
\text { semelhanças e diferenças com o fórum no Moodle. }\end{array}$ \\
\hline $18 / 05$ & $\begin{array}{l}\text { - Videoconferência entre os professores brasileiros e os acadêmicos da UNC. } \\
\text { - Discussão oral sobre a experiência vivenciada. }\end{array}$ \\
\hline $02 / 03$ a $27 / 05$ & $\begin{array}{l}\text { - Fórum Participação espontânea: espaço que esteve aberto durante todo o curso } \\
\text { para que os participantes pudessem propor temas para discussão, sem caráter } \\
\text { avaliativo, livre. Tivemos quatro propostas, com adesão dos demais cursistas. } \\
\text { - Fórum para tirar dúvidas. }\end{array}$ \\
\hline
\end{tabular}

Fonte: elaborado pela autora

Levando em conta os princípios vigotskianos sobre aprendizagem e desenvolvimento da linguagem a partir do contato com "pares mais desenvolvidos", a engrenagem central de nossa pesquisa foi propiciar a interação de professores brasileiros em formação continuada, com carência de aperfeiçoamento no domínio de conceitos científicos específicos da área 
(e no próprio uso da língua), com professores argentinos em formação inicial, em contato mais frequente com teorias atuais, porém menos experientes no que se refere à prática docente, ao exercício diário em sala de aula. Tendo ainda o objetivo comum de desenvolver-se no uso das novas tecnologias de informação e comunicação (NTIC).

Atuei na coordenação e tutoria no curso, tivemos um professor argentino, mestrando do programa Maestría en Enseñanza de Español como Lengua Extranjera da Facultad de Lenguas da UNC - que atuou como colaborador no curso - e 32 participantes, sendo dezesseis argentinos em formação inicial e dezesseis brasileiros em formação continuada, que atuaram como alunos/cursistas.

Os dezesseis professores brasileiros atuam em escolas públicas e possuem habilitação em Letras Português e Espanhol. Desses, dez fazem parte do Quadro Próprio do Magistério (QPM) do estado do Paraná e seis são seletistas, assumindo as aulas pelo Processo de Seleção de Servidores (PSS).

Dos dezesseis participantes argentinos, oito informaram fazer o curso Profesorado de Español Lengua Materna y Lengua Extranjera (quatro no segundo, um no terceiro e três no quarto ano da graduação); sete, fazer o curso Licenciatura en Español Lengua Materna y Extranjera (seis no segundo e um no quinto ano) e uma participante já havia concluído a licenciatura e estava como colaboradora no curso preparatório para ingresso na Facultad de Lenguas.

Visando proteger a identidade dos participantes, os identificaremos por uma sigla composta por letras e número. Sendo $\mathrm{P}$ (participante) + A (Argentina) ou B (Brasil) + um número que o identifica.

Temos então PB01, PB02, PB03, PB04, PB05, PB06, PB07, PB08, PB09, PB10, PB11, PB12, PB13, PB14, PB15 e PB16 como representações dos participantes brasileiros, em formação continuada.

Do mesmo modo, os participantes argentinos em formação inicial são representados por PA01, PA02, PA03, PA04, PA05, PA06, PA07, PA08, PA09, PA10, PA11, PA12, PA13, PA14, PA15 e PA16.

Nos mapas mentais, que utilizamos em nossas análises, a tutora é representada pela sigla TRA.

\section{Dados e análises}

Com a finalidade de responder nossos questionamentos sobre as relações entre as interações mediadas pelo gênero fórum virtual educacional 
(e demais recursos disponibilizados no Moodle), e a aprendizagem de conteúdos propostos e, levando em consideração nossos objetivos ao selecionarmos e planejarmos o uso de cada recurso do Moodle, elaboramos nossos critérios para análise, conforme exposto no Quadro 3.

\section{QUADRO 3 - Critérios para análise dos recursos utilizados no Moodle}

\begin{tabular}{|c|c|c|}
\hline Recurso & Objetivo & Critérios de análise \\
\hline Fórum (Foro) & $\begin{array}{l}\text { Promover a interação entre os } \\
\text { participantes, a partir de temas } \\
\text { propostos e de leituras realizadas. }\end{array}$ & $\begin{array}{l}\text { Analisar se os participantes, além de } \\
\text { responderem a questão central de cada fórum, } \\
\text { interagem entre si, tecendo comentários de } \\
\text { concordância (ou não), de esclarecimentos e } \\
\text { com novas interrogações. }\end{array}$ \\
\hline $\begin{array}{l}\text { Arquivo } \\
\text { (Archivo) }\end{array}$ & Disponibilizar textos para leitura. & $\begin{array}{l}\text { Verificar se os textos são referenciados durante } \\
\text { as discussões nos fóruns. }\end{array}$ \\
\hline \multirow[t]{2}{*}{ Pasta (Carpeta) } & $\begin{array}{l}\text { Organizar os textos dos diferentes } \\
\text { temas discutidos }\end{array}$ & $\begin{array}{l}\text { Verificar se a organização dos textos em pastas } \\
\text { temáticas facilitou a busca de cada grupo. }\end{array}$ \\
\hline & $\begin{array}{l}\text { Disponibilizar os resumos feitos pelos } \\
\text { diferentes grupos. }\end{array}$ & $\begin{array}{l}\text { Investigar se há referências dos resumos nos } \\
\text { comentários nos fóruns. }\end{array}$ \\
\hline $\begin{array}{l}\text { Rótulo } \\
\text { (Etiqueta) }\end{array}$ & $\begin{array}{l}\text { Disponibilizar textos com imagens } \\
\text { estáticas e em movimento (vídeos) para } \\
\text { facilitar a relação entre os conceitos } \\
\text { estudados e as ações de linguagem, } \\
\text { fornecendo mais subsídios para as } \\
\text { discussões nos fóruns. }\end{array}$ & $\begin{array}{l}\text { Analisar a relação que se estabelece entre os } \\
\text { textos com imagens e os temas (conceitos) } \\
\text { discutidos em cada fórum. } \\
\begin{array}{l}\text { Investigar como o uso desses recursos nas } \\
\text { atividades da tutora reflete nas atividades } \\
\text { elaboradas pelos participantes. }\end{array}\end{array}$ \\
\hline $\begin{array}{l}\text { Agrupamento } \\
\text { (agrupamiento) }\end{array}$ & $\begin{array}{l}\text { Promover a interação em grupos } \\
\text { menores para elaboração de uma } \\
\text { proposta temática de discussão coletiva. } \\
\begin{array}{l}\text { Possibilitar que diferentes conceitos } \\
\text { sejam simultaneamente discutidos. }\end{array}\end{array}$ & $\begin{array}{l}\text { Investigar como ocorre a interação nesses } \\
\text { grupos menores e que tipos de interação o } \\
\text { fórum na função agrupamento medeia. } \\
\begin{array}{l}\text { Analisar se ocorre aprendizagem dos conteúdos } \\
\text { propostos para discussão em cada grupo. }\end{array}\end{array}$ \\
\hline Tarefa (Tarea & $\begin{array}{l}\text { Possibilitar o envio do resumo das } \\
\text { leituras e das discussões que cada grupo } \\
\text { realizou. }\end{array}$ & $\begin{array}{l}\text { Verificar a realização (ou não) da tarefa e a } \\
\text { participação do grupo nessa atividade. }\end{array}$ \\
\hline e-mail (correo) & $\begin{array}{l}\text { Informar sobre atividades em } \\
\text { andamento no curso. } \\
\begin{array}{l}\text { Enviar tutoriais para uso da plataforma } \\
\text { Moodle. }\end{array} \\
\text { Assessorar os que encontrassem } \\
\text { dificuldades para realização das } \\
\text { atividades }\end{array}$ & $\begin{array}{l}\text { Analisar como ocorreram as interações } \\
\text { através do e-mail e quais foram as principais } \\
\text { dificuldades relatadas pelos participantes. }\end{array}$ \\
\hline
\end{tabular}

Fonte: elaborado pela autora 
Selecionamos, para apresentar neste artigo, a análise das atividades realizadas por meio da função Agrupamento ${ }^{8}$, disponível no Moodle a partir de 2011 e utilizado, pela primeira vez na UEL, em nosso curso.

Esse recurso foi de grande relevância, visto que, agrupados em menor número, os alunos discutem com mais profundidade alguns conceitos científicos e, a partir de então, elaboram uma proposta de discussão para todos do curso. Apropriam-se, desse modo, do gênero fórum virtual de discussão, deixando este de ser um artefato para tornar-se um instrumento mediador (SCHNEUWLY, 2010).

A tutora disponibiliza leituras e faz questionamentos diferentes para cada grupo, de acordo com os conceitos que lhes foram atribuídos a discutir e elaborar uma questão. Os fóruns grupais também estão marcados pela forte participação da tutora.

Com o objetivo de aproximar o leitor de nosso contexto de geração de dados, apresentamos um panorama de cada agrupamento e, posteriormente, selecionamos produções que nos possibilizam observar as interações, geradoras de aprendizagem, mediadas pelo fórum virtual educacional inserido em um AVA com função agrupamento.

Formamos os grupos equilibrando o número de argentinos e brasileiros, do modo apresentado no Quadro 4.

QUADRO 4-Grupos e seus integrantes

\begin{tabular}{|ll|}
\hline \multicolumn{1}{|c|}{ Grupo } & \multicolumn{1}{c|}{ Integrantes } \\
\hline 1 - Géneros textuales/tipos de texto & PA07, PA09, PA14, PB07, PB10, PB13, PB16 \\
\hline 2 - Contexto de producción & PA02, PA05, PA08, PB01, PB09, PB11 \\
\hline 3 - Enseñanza de lenguas & PA06, PA10, PA12, PB02, PB03, PB05 \\
\hline 4- Los impactos sociales de los textos & PA04, PA11, PA13, PB06, PB08, PB14 \\
\hline 5 - Capacidades de lenguaje & PA03, PA15, PA16, PB04, PB12, PB15 \\
\hline
\end{tabular}

Fonte: elaborado pela autora

\footnotetext{
${ }^{8}$ Agradecemos ao prof. dr. Pedro Paulo da Silva Ayrosa, diretor do Laboratório de tecnologia Educacional do Núcleo de Educação a Distância Labted/Nead da UEL, por sua dedicação em desbloquear o recurso Agrupamento da plataforma Moodle, para que pudéssemos utilizá-lo em nosso curso.
} 
Cada grupo teve por atividades: ler artigos relacionados ao tema; discutir, no fórum do grupo (a partir de uma questão proposta pela tutora), tópicos relacionados à leitura dos artigos e aos vídeos de anúncio publicitário disponíveis na página inicial de nossa sala Moodle; produzir um resumo escrito e propor tema/questão de fórum a todos os participantes do curso.

Visando exemplificar o intenso movimento de interação que ocorreu nos agrupamentos, apresentamos o mapa mental do grupo 1:

MAPA MENTAL 1 - Fórum do grupo 1: Tipos de textos/Géneros textuales

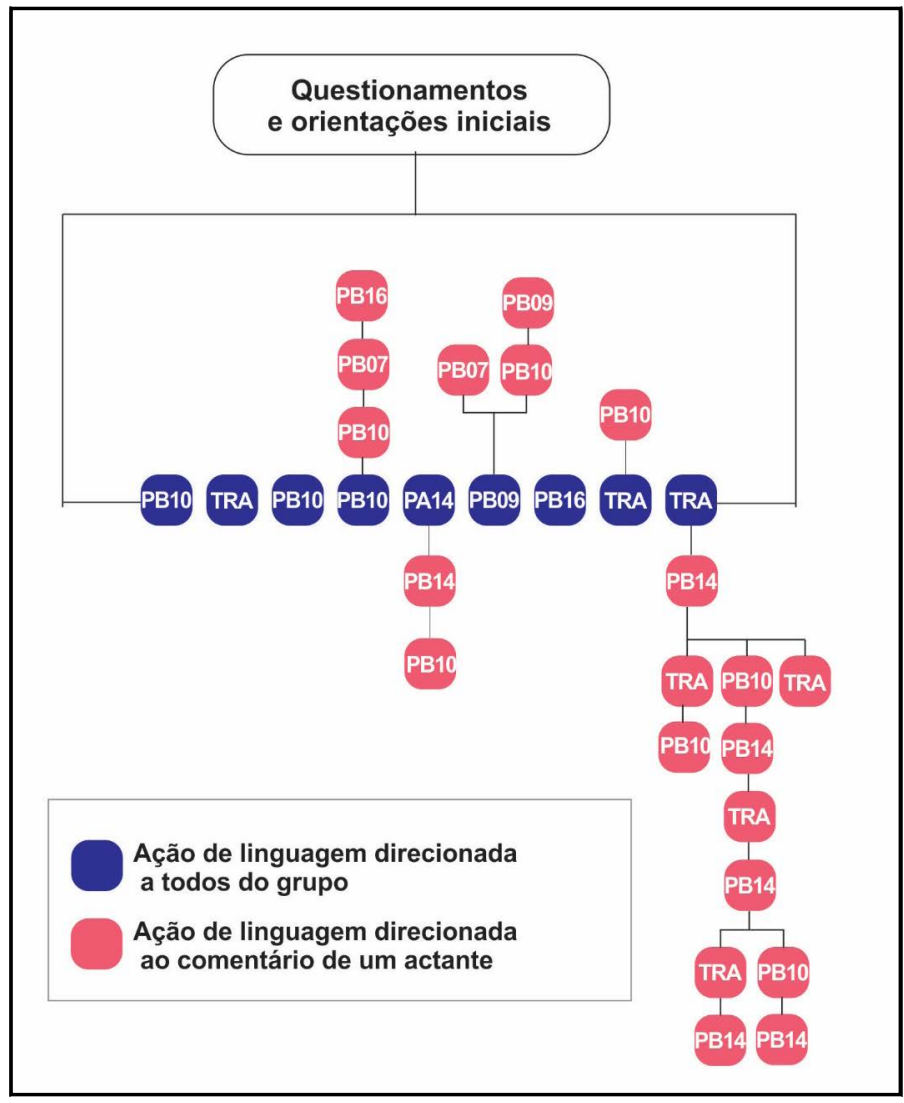

Fonte: elaborado pela autora

Chamou-nos atenção, no grupo 1, uma postagem de PB10 que, além das leituras indicadas, acatou a sugestão de buscar outras fontes. Fazemos agora uma comparação entre o post que PB10 inseriu no fórum "Conceptos" 
(que foi aberto a todos e tinha por objetivo conhecer a definição que os participante dariam a conceitos como: linguagem, língua, texto, tipos/ sequências de textos e gêneros textuais) e essa nova produção, feita após as orientações de leitura da tutora e de uma proposta de atividade que exige maior engajamento. Temos por objetivo observar e analisar a evolução da actante nessa ZDP, cujo objetivo é potencializar seu desenvolvimento; oferecendo condições para que ela alcance um nível que não atingiria sem a ajuda de outro.

\section{Re: Foro: Conceptos}

PB10 - lunes, 25 de marzo de 2013, 20:07

\section{Vamos intentar exponer las ideas...}

Lengua: códigos lingüisticos - palabras - las cuales producen la comunicación.

Lenguaje: representación del pensamiento - interacción entre personas - comunicación.

Para tanto, no podemos aislar un pensamiento del otro, pues para un acto comunicativo se cumplir es necesario la comunicación, abi si es imprescindible utilizarse de medios disponibles para eso. De esa forma los géneros textuales pueden venir de encuentro con la enseñanza y aprendizaje de una lengua, ya que cada género se presenta con una gama diversa de posibilidades.

Creo que discurso es todo el acto comunicativo, entonces independe del modo o medio, puede ser en lenguaje coloquial, culta, señales, gestos, lectura, escritura, lenguaje mista e otras, así siendo lengua/ lenguaje es comunicación.

\section{Re: Foro Grupo 1: Textos/Géneros}

PB10 - sábado, 6 de abril de 2013, 20:07

Hola TRA y colegas!

Después de leer los textos, reflexionary buscar otras fuentes de pesquisa, exteriorizo mis ideas, todavía estoy dudosa de mi contextualización...

Narración es una secuencia textual que podemos percibirla en otros géneros como por ejemplo: las leyendas y otros géneros literarios como la prosa poética pues la prosa poética constituye un género con expresión libre, así como la poesía. Distinguir un género de otro no es tarea tan sencilla así, pues muchas veces confundimos los tipos de textos con géneros textuales.

Se acredita que para distinguir un género textual de otro es imprescindible que elijamos cual es el propósito y cuál es la aplicabilidad la cual queremos obtener, 
cuáles serán los interlocutores, su edad y principalmente el objetivo a lograr. A veces para que haya la comunicación es necesario que busquemos una actividad la cual tenga el objetivo de ensenar la lengua de una manera más eficiente. Conforme afirma Silva "El acceso a distintos géneros textuales es de suma importancia para que criemos un 'banco de dados'y, con eso, podemos elegir cada uno de ellos en cada contexto, propiciando una elección adecuada para las producciones textuales para cada situación comunicativa".

Segundo Bakbtin/Bajtín, las esferas de la actividad humana es la integración que los bumanos se dan por intermedio de la palabra, o sea la comunicación. Los géneros discursivos ennoblecen esta comunicación por presentar una variedad múltiple de posibilidades comunicativas. Hoy día es casi imposible baber comunicación efectiva, sin los géneros discursivos, pues la comunicabilidad exige una gama de inferencias escritas, auditivas, de lecturas y otras que no se puede quitar ninguna posibilidad para el entendimiento, enseñanza y aprendizaje de una lengua.

Aún los géneros textuales son definidos por propiedades socio comunicativas, abarca un conjunto accesible, posibilitando designaciones concretas (estilo, contenido, composición, y función). Ejemplos: telefonema, cartas, receta, novelas, clases virtuales y otros.

Asi siendo es imprescindible que observemos a gran diversidad de los géneros textuales y todas las probabilidades de inferencias que podemos añadir en cada uno de ellos para el uso de una lengua. Citando Bajtín, "La riqueza y diversidad de los géneros discursivos es inmensa, porque las posibilidades de la actividad humana son inagotables... y crece a medida de que se desarrolla".

O primeiro post denota o desenvolvimento real de PB10 no dia 25 de março de 2013. Ela conceitua os termos com palavras soltas e, talvez por faltar conhecimento, foge da definição de gênero, apresentando uma resposta bastante evasiva: los géneros textuales pueden venir de encuentro con la enseñanza y aprendizaje de una lengua, ya que cada género se presenta con una gama diversa de posibilidades.

O curso como um todo representa a ZDP, processo de interação com pares mais desenvolvidos, por meio de aprendizagem orientada e de compartilhamento de conhecimentos socio-historicamente construídos. Além da escolha que a tutora faz dos textos e do modo como elabora a atividade norteadora, Bakhtin, Marcuschi e Silva também atuam como pares mais desenvolvidos, contribuindo para que PB10 atinja seu nível de desenvolvimento potencial; visto que ela interage com os autores por meio de seus textos. 
O segundo post, inserido dia seis de abril de dois mil e treze, representa o novo nível de desenvolvimento real de PB10. Como afirma Vigotski (2002, p. 80), "os novos e elevados conceitos transformam o significado dos conceitos inferiores".

Retomando Friedrich (2011), em seus estudos vigotskianos, ressaltamos que é por meio do ensino dos conceitos científicos que ocorre o desenvolvimento das funções superiores da mente, e vice-versa: uma mente mais desenvolvida compreende melhor os novos conceitos científicos com os quais se depare (rever Figura 3).

As condições biológicas de PB10 praticamente não se alteram de 25 de março a 6 s de abril, o que muda é o ambiente no qual se insere, que lhe proporciona o contato com novas leituras e o engajamento em uma atividade que requer conhecimentos para expor as ideias e reflexão para agir.

A interação entre tutora, PB10 e conhecimento é mediada pelo gênero fórum virtual educacional, inserido no Moodle. Atestando o que defende Schneuwly (2010), o gênero pode ser considerado um instrumento psicológico de mediação e um fator de desenvolvimento das capacidades individuais. O post de PB10 foi lido pelos demais participantes de seu grupo, viabilizando uma discussão que resultou na boa execução da tarefa de propor um fórum para todos do curso.

Em relação às propostas de fórum para todos do curso, o grupo 1 inseriu um vídeo e um texto e levantou questionamentos relacionados aos conceitos de gêneros e tipos de textos; o 2 também disponibilizou um vídeo e elaborou questões a ele relacionadas; o 3 inseriu uma imagem bemhumorada e indagou sobre o ensino de línguas e o uso das novas tecnologias; o 4 postou apenas um questionamento escrito, porém, a actante PA05, ao responder à questão, inseriu dois vídeos de anúncios publicitários; o grupo 5 não fugiu à regra: disponibilizou um vídeo e questionou sobre as capacidades de linguagem.

Como afirma Vigotski (1994), na ZDP, a imitação é algo positivo, visto que o aprendiz está se espelhando em modelos aceitos no contexto de produção. Ressaltamos que o grupo 1 agiu também por meio de um poema, gênero textual que não havia sido mobilizado pela tutora, ou seja, a partir da imitação, o actante exercita suas capacidades e é a capaz de criar. Os vídeos propostos também não foram todos de anúncios publicitários, como nas apresentações da tutora - o grupo 2 apresentou um vídeo didático, e o 5, um vídeo com sátiras musicalizadas. 
Nas discussões em grupos, entre as propostas sugeridas, encontramos questões com tirinhas. Fato que também indica que os aprendizes, vivenciando uma $Z D P$, conseguem compreender as variáveis aceitas pelo gênero. Segundo Vigotski (1994, p. 99), “uma compreensão plena de ZDP deve levar a reavaliação do papel da imitação no aprendizado".

A apropriação do gênero aparece evidenciada nas ações de alguns participantes, permitindo-nos afirmar que a interação entre tutora/ participantes e participantes entre si possibilita o desenvolvimento dos conceitos científicos necessários para agir socialmente por meio desse gênero.

Do grupo 1, as participantes PB10 e PA14 acompanham a discussão no fórum proposto por seu grupo e, ao final, PA14 faz um fechamento, retomando os conceitos discutidos e sanando eventuais dúvidas. $\mathrm{O}$ engajamento na atividade, por parte de PB10 e PA14, resulta na proposta de discussão com maior número de postagens, sendo também elogiadas pelos colegas de curso. No Mapa Mental 2, podemos observar essa presença ativa das alunas.

MAPA MENTAL 2 - Fórum proposto pelo grupo 1

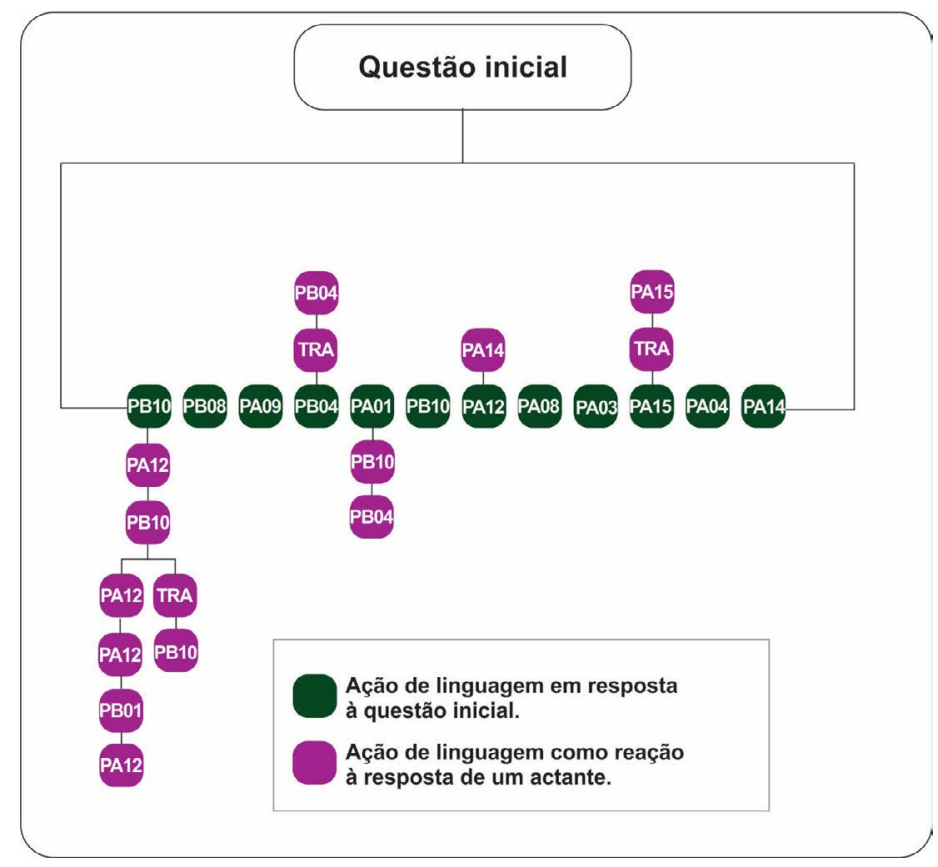

Fonte: elaborado pela autora 
A esquematização do gênero é absorvida pelas participantes. Como afirma Schneuwly (2010), o artefato se torna instrumento e passa a ser mediador da atividade. $\mathrm{O}$ fórum se torna mediador de uma atividade de ensino/aprendizagem (de conceitos relacionados ao ensino de língua espanhola).

Em contrapartida, o grupo 2, apesar de discutir com propriedade os conteúdos propostos e ter três opções para debate, acaba por escolher um questão que se distancia dos conceitos discutidos e do que se apresenta no resumo realizado pelo grupo. Talvez por este fato tenha sido o grupo com menor adesão. Outro fator que pode ter influenciado é a inserção de um vídeo didático com baixo grau de criatividade, tornando-se cansativo assistilo duas ou três vezes para responder os questionamentos feitos pelo grupo.

O Mapa Mental 3 nos permite visualizar o baixo grau de participação que temos no fórum proposto pelo grupo 2.

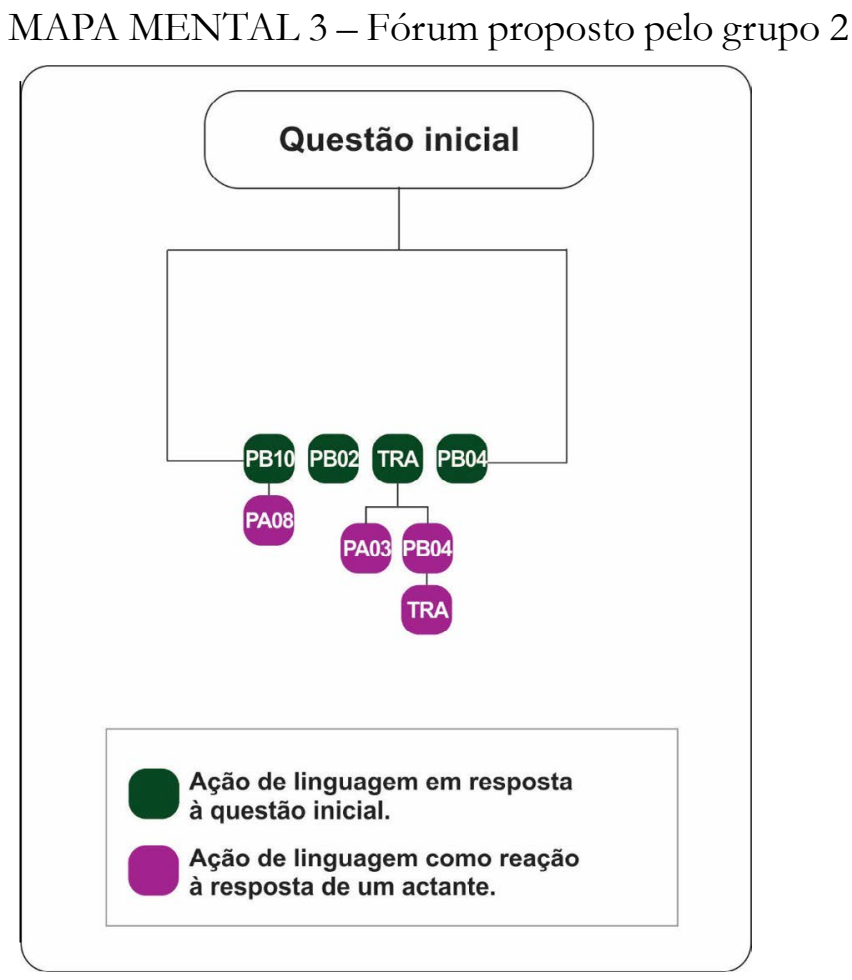

Fonte: elaborado pela autora 
PA08 é a única integrante do grupo que interage no fórum; PA04, que sugeriu a proposta de discussão, se ausenta, diferentemente do que ocorre no grupo 1.

A tutora, diante da carência de esclarecimentos, insere uma extensa postagem no fórum, abrangendo os conteúdos discutidos no grupo:

El contexto de producción, tema debatido por el grupo 2, es fundamental para la comprensión, producción y análisis de textos.

El contexto físico (emisor/ receptor/ lugar físico/fecha y horario) y el contexto sociosubjetivo (enunciador/destinatario/lugar social momento histórico / intencionalidad) forman parte del contexto de producción.

Analicemos este ejemplo:

Contexto fisico:

Emisor: Vera Lucia Lopes Cristovão, mujer, brasileña...

Receptores ("co-emisores"): hombres y mujeres, de distintas edades. (28 personas)

Lugar físico: salón con sillas, mesa, aire acondicionado, proyector, pantalla ... ubicado en la UEL, Av. Celso...

Fecha y horario: todos los jueves de las 14h a las 16h, del primer semestre de 2013.

Contexto de socio-subjetivo:

Enunciador: profesora de la asignatura "Géneros y enseñanza..." del programa de posgrado en Estudios del Lenguaje (PPGEL)

Destinatarios ("co-enunciadores"): alumnos de maestría/ máster y doctorado. La mayoría ya imparte clases de lengua materna o extranjera. Buscan el perfeccionamiento profesional.

Lugar social: universidad como un espacio de búsqueda y construcción colectiva de nuevos saberes. [...]

Intencionalidad: Leer, reflexionary discutir sobre la enseñanza de lenguas con base en el enfoque interactivo, cuyas herramientas son los géneros textuales...

Todos los jueves, Vera se enuncia como profesora y nosotros, mis colegas y yo, como alumnos. Este contexto de producción más formaly jerarquizado no permite que uno bable tonterias, que sea demasiado chistoso...

Puesto terminan las clases, Vera y yo seguimos para una pequeña sala, donde recibo instrucciones para mi tesis de maestría, en este momento ella se enuncia como mi directora.

Cuando llega en su casa ¿cómo se enuncia Vera? Es otro lugar físico, otro horario... otro lugar social... Se enuncia como madre, como esposa... 
No perdemos nuestra esencia, pero el cambio de contexto cambia nuestras funciones y la manera como nos enunciamos.

Si tenemos por objetivo formar alumnos más críticos, es necesario que les enseñemos como observar el contexto de producción.

A pesar das limitações do fórum, essa intervenção da tutora promove a tomada de consciência, por parte de uma das alunas do curso, em relação aos papéis sociais que assume:

!Qué interesante! Nunca babia pensado en esto TRA, cuando estoy en la escuela me enuncio como profe; en casa, como madre y esposa; en el supermercado, como ama de casa; en una tienda comprando ropas, como consumidora; en la casa de mi madre me enuncio como bija... (PB04).

$\mathrm{Na}$ videoconferência, PB08 e PB12, que não se inseriram nesse fórum, comentam o exemplo dado pela tutora ao citar sua orientadora em seus diferentes papéis sociais; revelam que, apesar de não terem comentado, entraram no fórum, leram a postagem e tiveram uma atitude responsiva, até então, silenciosa. Bakhtin (2003, p. 290-291), discorrendo sobre o conceito de atitude responsiva ativa, afirma que "uma resposta fônica (ou escrita), claro, não sucede infalivelmente ao enunciado fônico (ou escrito) que a suscita".

Não é possível quantificar as atitudes responsivas, visto que elas podem ser manifestas ou silenciosas. O que podemos observar, comparando os fóruns propostos pelos grupos 1 e 2, é que, quanto maior a compreensão dos esquemas de utilização de um instrumento, maior sua eficácia. Retomamos a citação de Schneuwly (2010, p. 22), segundo o qual o instrumento "não é eficaz senão à medida que se constroem, por parte do sujeito, os esquemas de sua utilização".

O grupo 1, com intensa interação, releva ter construído melhor esses esquemas, considera os destinatários e elabora uma proposta que os atrai. Os grupos 3 e 4 apresentaram desempenho bastante semelhante ao do grupo 1, com intensa interação entre os proponentes das questões e os demais actantes do curso.

Já o grupo 5, apesar do acompanhamento dos proponentes, teve baixa adesão. Atribuímos isso ao fato de que, além da questão apresentar um deslocamento em relação aos conteúdos discutidos no grupo (o que não ocorre nos grupos 1, 3 e 4), exige conhecimentos culturais que não foram

${ }^{9}$ Inserimos (ou escrita) e (ou escrito) na citação de Bakhtin. 
disponibilizados em sua elaboração. A tutora, assim como no grupo 2, fez inserções visando provocar reflexão que gere aprendizagem dos conteúdos propostos.

Não podemos afirmar que todos os participantes - ou mesmos os concluintes - do curso se apropriaram do gênero fórum como instrumento psicológico de mediação; o que trazemos, com base em nossos dados, é que essa possibilidade existe.

\section{Considerações finais}

Realizar esta pesquisa foi extremamente desafiador, além de articular formação inicial e continuada, unimos professores de dois países, cada qual com seus valores culturais e socioeducativos, para interagir visando a aprendizagem de conteúdos relacionados ao ensino de línguas estrangerias, em especial de língua espanhola.

Outro desafio foi utilizar um AVA para realização do curso, mobilizando recursos com quais os professores parecem não estar familiarizados. Foram muitas as dúvidas, tanto para se cadastrar quanto para compreender as características desse novo ambiente de aprendizagem. As dificuldades também apareceram na elaboração das atividades e na busca por referências adequadas, cada passo foi planejado levando em conta que a interação ocorreria em um meio virtual.

Com o curso já em andamento, nossa preocupação esteve em acompanhar e fazer intervenções que contribuíssem para melhor compreensão dos conteúdos e, concomitantemente, motivassem os participantes a se engajarem nas atividades propostas.

A função Agrupamento, do Moodle, nos permitiu propor fóruns específicos, reunindo os alunos em números menores para atividades de leituras e tarefas que não tiveram um fim em si mesmas, mas beneficiaram a todos do curso. Essa atividade significativa os fez mobilizar os conteúdos de modo consciente e crítico, agindo por meio de recursos até então desconhecidos, tendo que, para isso, com a ajuda da tutora, desenvolver novos conhecimentos que, a nosso ver, geraram desenvolvimento.

Os resultados nos surpreenderam. Olhando os mapas mentais é possível observar a quantidade de produções que temos nos fóruns - a maioria é fonte de marcas discursivas e linguístico-discursivas que revelam os processos de aprendizagem desencadeados a partir da interação mediada pelos recursos disponíveis no Moodle. 
O relevante diálogo entre professores de espanhol - brasileiros em formação continuada e argentinos em formação inicial - promoveu tanto a aprendizagem dos conteúdos quanto as capacidades para agir em um ambiente virtual. Ressaltamos que esse diálogo permaneceu até o final do curso, havendo um surpreendente equilíbrio entre número de concluintes. Os mapas mentais também nos permitem visualizar a presença desses participantes em constante interação.

Podemos concluir que as interações entre tutora/participantes, e estes entre si, mediadas pela plataforma Moodle, estabelecem relações diretas com a aprendizagem, visto que:

a) Os fóruns propostos pela tutora servem de base para que os alunos, além de discutir os conteúdos propostos, estejam inseridos em um contexto de uso de NTIC, reconhecendo-o e, gradativamente, dele se apropriando, ou seja, a interação promove a aprendizagem de como agir por meio do gênero fórum virtual educacional.

b) Nos fóruns na função agrupamento fica ainda mais evidente a relação entre interação e aprendizagem. A interação dos alunos com a tutora - por meio do exercício das atividades que esta propõe - e dos alunos entre si, dialogando sobre as leituras e a elaboração de uma questão provocadora, resulta na aprendizagem dos conteúdos sugeridos.

c) Os fóruns propostos pelos alunos evidenciam que aprendem como inserir uma sugestão de discussão, dominando um recurso tecnológico que até então não sabiam como utilizar. A interação tutora/participantes resulta na aprendizagem de técnicas de uso de novos recursos tecnológicos. Além disso, temos claros exemplos de apropriação do gênero fórum virtual enquanto instrumento psicológico de mediação.

Como em toda pesquisa, encontramos pontos que precisam ser mais bem explorados e analisados em futuros trabalhos. Assinalamos a necessidade de observamos com maior acuidade a relevância do tutor em AVA, (visto que há muitos relatos de cursos on-line que não geram esses movimentos de interação) e de discorrer com mais profundidade sobre a relação entre formação inicial e continuada.

Esperamos que essa pesquisa possa contribuir, ainda que modicamente, para que essa experiência de aprendizagem, que articula diferentes países, possa ser melhorada e estendida para outros contextos de formação de professores de línguas estrangeiras. 


\section{Referências}

ARAÚJO, J. C. Internet e ensino: novos gêneros, outros desafios. Rio de Janeiro: Lucerna, 2007.

ARAÚJO, J. C.; COSTA, N. Momentos interativos de um chat aberto: a composição do gênero. In: ARAÚJO, J. C. Internet e ensino: novos gêneros, outros desafios. Rio de Janeiro: Lucerna, 2007. p. 21-34.

BAKHTIN, M. Os gêneros do discurso. In: BAKHTIN, M. Estética da criação verbal. São Paulo: Martins Fontes, 2003. p. 261-306.

BAKHTIN, M.; VOLOCHINOV, V. N. Marxismo e filosofia da linguagem. 12. ed. São Paulo: Hucitec, 1986.

BRONCKART, J. P. Atividade de linguagem, textos e discursos: por um interacionismo sócio-discursivo. Tradução de Anna Rachel Machado e Péricles Cunha. São Paulo: Educ, 2003.

BRONCKART, J. P. Os gêneros de texto e os tipos de discurso como formato das interações propiciadoras de desenvolvimento. In: MACHADO, A. R.; MATENCIO, M. L. M. (Org.). Atividade de linguagem, discurso e desenvolvimento humano. Campinas: Mercado de Letras, 2006.

COSCARELLI, C. V. Linkando as ideias dos textos. In: ARAÚJO, J. C.; DIEB, M. (Org.). Letramentos na web: gêneros, interação e ensino. Fortaleza: Edições UFC, 2009. p. 13-20.

CRISTOVÃO, V. L. L.; SANTOS, L. M. A. Prática de linguagem do meio virtual e a educação inicial de professores de línguas: o gênero textual fórum de discussão Educacional. In: CALVO, L. C. S. et al. (Org.). Reflexões sobre ensino de linguas e formação de professor no Brasil: uma homenagem à professora Telma Gimenez. Campinas: Pontes, 2013. p. 265-289.

DAVID, P. B. et al. Gêneros assíncronos: instrumentos de interação em ambientes virtuais de aprendizagem. In: CONGRESSO DA SOCIEDADE BRASILEIRA DE COMPUTAÇÃO, 26., 2006, Campo Grande. Anais... Campo Grande: Universidade Federal do Mato Grosso do Sul, 2006. Disponível em: < https:/ / bit. ly/2Mxc31s>. Acesso em: 6 jan. 2013.

FRIEDRICH, J. Lev Vigotski mediação, aprendizagem e desenvolvimento: uma leitura filosófica e epistemológica. São Paulo: Mercado das Letras, 2011.

KINCHELOE, J. L.; MCLAREN, P. Repensando a teoria crítica e a pesquisa qualitativa. In: DENZIN, N. K.; LINCOLN, Y. S. (Ed.). O planejamento da pesquisa qualitativa: teorias e abordagens. Porto Alegre: Artmed, 2006. p. 281-313. 
LIMA, A. A argumentatividade no e-gênero fórum de discussão: uma estratégia para produção em contexto escolar. In: SIMPÓSIO HIPERTEXTO E TECNOLOGIA NA EDUCAÇÃO: REDES SOCIAIS E APRENDIZAGEM, 3., 2010, Recife. Anais... Recife: Universidade Federal de Pernambuco, 2010. p. 1-22.

LINCOLN, Y.; GUBA, E. G. Controvérsias paradigmáticas, contradições e confluências emergentes. In: DENZIN, N. K.; LINCOLN, Y. S. (Ed.). Planejamento da pesquisa qualitativa. Porto Alegre: Artmed, 2006. p. 169-192.

LÓPEZ GARCÍA, P.; LACLETA, M. L. Moodle: difusión y funcionalidades. Zaragoza: Universidad de Zaragoza, 2006. Disponível em: $<$ http://unizar.es/eees/ innovacion06/COMUNIC_PUBLI/BLOQUE_III/CAP_III_10.pdf $>$.

MARCUSCHI, L. A. Gêneros textuais emergentes no contexto da tecnologia digital. In: MARCUSCHI, L. A.; XAVIER, A. C. (Org.). Hipertexto e gêneros digitais: novas formas de construção do sentido. 3. ed. Rio de Janeiro: Lucerna, 2010. p. 15-80.

OLIVEIRA, M. K. Vygotsky - aprendizado e desenvolvimento: um processo sóciohistórico. São Paulo: Scipione, 1993.

SANTOS, L. M. A. Gêneros digitais na educação inicial do professor de língua inglesa como instrumentos de (trans)formação. 2012. Dissertação (Mestrado em Estudos da Linguagem) - Universidade Estadual de Londrina, Londrina, 2012.

SCHNEUWLY, B. Gêneros e tipos de discurso: considerações psicológicas e ontogenéticas. In: SCHNEUWLY, B.; DOLZ, J. (Org.). Gêneros orais e escritos na escola. 2. ed. Campinas: Mercado de Letras, 2010.

SILVA, I. M. M. Gêneros digitais: navegando rumo aos desafios da educação a distância. Revista Eletrônica do Centro de Estudos em Educação e Linguagem, Recife, v. 1, n. 1, p. 125-143, jan./jun. 2011.

VALENTE, J. A. O papel da interação e as diferentes abordagens pedagógicas de Educação à distância. In: MILL, D.; PIMENTEL, N. (Org.). Educação a distância: desafios contemporâneos. São Carlos: EdUFSCAR, 2013. p. 25-39.

VIGOTSKI, L. S. A formação social da mente: o desenvolvimento dos processos psicológicos superiores. São Paulo: Martins Fontes, 1994.

VIGOTSKI, L. S. Pensamento e linguagem. São Paulo: Martins Fontes, 2002.

Data de submissão: 05/01/2018. Data de aprovação: 20/07/2018. 
